\title{
Practical Considerations in Gene Therapy for HIV Cure
}

\author{
Rodica Stan • John A. Zaia
}

Published online: 22 January 2014

(C) The Author(s) 2014. This article is published with open access at Springerlink.com

\begin{abstract}
Despite the success of antiretroviral therapy in suppressing HIV-1 replication and extending the life of HIV-1 infected individuals, this regimen is associated with risks for non-AIDS morbidity and mortality, requires life commitment, and has a high cost. In this context, gene therapy approaches that have the potential to cure HIV-1 infection present a clear option for eradication of the virus in the next decades. Gene therapy must overcome concerns related to its applicability to HIV-1 infection, the safety of cytotoxic conditioning required for cell-based approaches, clinical trial design, selection of gene-modified cells, and the restrictive cost of manufacturing and technology. These concerns are discussed herein in the context of the most relevant gene therapy studies conducted so far in HIV/AIDS.
\end{abstract}

Keywords HIV/AIDS · HIV · Gene therapy · CD4 T cell · Hematopoietic stem progenitor cell (HSPC) · Lentivirus · Vector $\cdot$ siRNA $\cdot$ Expense $\cdot$ Risk benefit analysis $\cdot$ HIV infection $\cdot$ HIV-1 replication · Cell-based approaches . HIV-1 reservoir $\cdot$ Challenges $\cdot$ Strategies

\section{Introduction}

The ultimate goal of a gene-therapy strategy for the cure of HIV/AIDS is to contribute a new set of immune cells that would be resistant to HIV-1 infection and would reconstitute the immune system. The recovered immune function would then simultaneously control infection and destroy the endogenous viral reservoir. The widespread use of antiretroviral

R. Stan · J. A. Zaia $(\bowtie)$

Department of Virology, Beckman Research Institute of City of

Hope, 1500 East Duarte Road, Duarte, CA 91010, USA

e-mail: jzaia@coh.org therapy (ART) has achieved partial success in this respect by controlling the HIV-1 infection in most individuals. ART improves the health and extends the life of HIV-1 infected individuals and reduces the rate of viral transmission from individual to individual. However, this regimen is associated with several comorbidities, requires strict compliance with a lifelong drug regimen, and has little impact on the elimination of the HIV-1 reservoir [1•]. Latently infected, resting CD4+ T cells have been shown to persist in HIV-1 infected individuals treated with ART who otherwise have minimal levels of virus in the plasma $[2,3 \cdot \bullet]$.

For the purposes of this discussion, it is assumed that use of gene-modified, autologous cell-based strategies have the potential to achieve the goal outlined above. The recent success in apparently curing HIV-1 infection using allogeneic cellbased approaches $[4 \cdot, 5 \bullet, 6 \bullet]$, although remarkable, will not be considered here because of the expense and toxicity of this approach. Strategies using autologous CD4 T cells or hematopoietic stem progenitor cells (HSPC), although also complex, have a more direct path to the clinic in the non-malignant HIV/AIDS patient. In addition to these cell-based approaches, recent investigations have focused on (a) drugs that reactivate latent HIV-1 from resting CD4+ $\mathrm{T}$ cells prior to the therapeutic intervention to eradicate the virus [7], and (b) immune reagents, such as neutralizing antibodies $[8,9,10 \bullet \bullet, 11 \bullet]$, which enhance the anti-HIV-1 immune responses. These strategies are attractive and could well be used adjunctively with cellular therapy, but they will not be discussed here.

Autologous gene therapy-based strategies, while equally challenging in terms of practical application, have the potential to be relatively safe and would provide either a sterilizing cure, by completely eliminating the HV-1 reservoir, or a functional cure, by enabling long-term control over the virus in the absence of ART (ie, durable drug-free remission) [12]. 


\section{Gene Therapy Challenges}

Gene-therapy based approaches most commonly aim to create a robust HIV-1 resistant immune system by targeting viral or cellular elements necessary to suppress viral infection after transplantation of resistant T cells or HSPC. Such strategies ultimately protect progeny CD4+ T cells and other HIV-1 susceptible cells from further viral infection and lead to the restoration of the immune function. To achieve this goal, the transgene or a combination of genes of interest is cloned into a delivery vehicle, a viral, or nonviral vector, which is then delivered efficiently into the target cells (T cells or HSPC) ex vivo $[13 \bullet, 14]$. These genetically modified cells are then release tested for safety and quality control and then re-infused into the patient. Except for strategies whereby genetic modification occurs by transient exposure to nucleases $[15 \bullet, 16]$, most gene therapy approaches require long-term stable expression of the transgene in modified cells. Integrating and nonintegrating vectors are used and continue to be developed, each having their own unique advantages and disadvantages $[17,18]$. For example, integrating vectors deliver the transgene into host DNA with the promise of long-lived expression, whereas nonintegrating vectors have a shorter period of expression and thus minimize the theoretical risk of insertional mutagenesis [16]. Finally, engraftment of the gene-modified cells is a pre-requisite for the success of this approach, which most likely requires conditioning with chemotherapy or nonchemotherapy agents, prior to the transplant.

The field of gene therapy is making sustained efforts to design better strategies for efficient, safe and cost-effective gene delivery, to identify new molecular targets for improved antiviral effect, and to move toward clinical trials that test the safety and feasibility of these approaches (discussed in $[13 \bullet, 19])$.

\section{HIV-1 Gene Therapy Strategies}

A diverse array of transgenes to suppress HIV-1 functions or block the infectious cycle belong mostly to 2 groups of suppressors: nucleic acid-based and protein-based (reviewed in [20]). Current gene therapy strategies use combinations of different types of transgenes with viral and/or cellular targets that aim to completely neutralize HIV-1 functions at specific points in the infection cycle. In contrast to targeting a single step of HIV-1 infection, the advantage of inhibiting a number of critical steps in virus replication is that complete and effective suppression is more likely to achieve. In addition, use of combinations of different types of transgenes is also expected to prevent the emergence of HIV-1 variants that escape the gene-based strategy. A summary of published gene therapy clinical trials using these approaches is included with more details and references in Table 1.
RNA-Based Suppressors, Including RNA-Antisense, RNA Interference (RNAi), Ribozymes, and RNA Aptamers (Reviewed in [37, 38]

Newly transcribed RNA-antisense molecules bind to mRNA sequences and prevent translation of the encoded protein, thereby resulting in loss or reduction of gene function. In one of the earliest lentiviral-based gene therapy studies against HIV-1 infection, an antisense mRNA to HIV-1 env expressed from a lentiviral vector was safely used in the setting of T-cell immunotherapy [34]. Further studies with the product (VRX496-T; trade name Lexgenleucel-T) given as multiple infusions were performed more recently in patients with wellcontrolled HIV-1 infection [35•]. The antiviral effect of the product was evaluated in a subset of treated patients who underwent an analytical treatment interruption (ATI) of their antiviral medication, the idea being that the ATI allows selection of the gene-modified cells once the virus is again present in the plasma. The study demonstrated a reduction in the viral load and found that VRX496-T put antisense-mediated genetic pressure on the virus during infection.

RNA decoy molecules attempt to compete with specific HIV-1 RNA elements that bind viral proteins as part of the replication cycle by overexpressing their RNA homologs. TAR (TAT response element) and RRE (Rev-response element) are 2 such cis-acting factors that are necessary for proper function of the key HIV-1 regulatory proteins, Tat and Rev. These elements have been evaluated in clinical trials, 1 in transduced and transplanted marrow-derived hematopoietic stem cells in HIV-1 infected children [21] and 1 in CD34+ HSPC transduced and transplanted in HIV-1 infected patients with Non-Hodgkin's Lymphoma (NHL) who required autologous transplantation $[25 \bullet \cdot]$.

Ribozymes are RNA molecules that can cleave RNA targets at specific sequences and thus can be used to inactivate HIV-1 RNAs [17]. A ribozyme has been used as a component of combinatorial gene therapy in HIV-1 infected patients with NHL mentioned above [25••].

RNAi, which naturally occurs in a variety of organisms, including fungi, plants, insects, protozoans and mammals [39], is based on a cellular process, in which doublestranded RNA (dsRNA) induces a post-transcriptional degradation of homologous transcripts. Several studies have demonstrated that the functional unit of RNAi, the siRNAs, can elicit sequence-specific target downregulation [40]. The successful expression of siRNAs in mammalian cells has allowed RNAi to be applied as a potent mechanism for inhibition of HIV-1 infection and anti-HIV therapy [41, 42]. The siRNA can be used as an antiviral agent either by transfection of the preformed siRNAs [43] or by intracellular expression of siRNAs. The latter approach has been utilized in a gene therapy setting, providing anti-HIV-1 RNAs to hematopoietic cells susceptible to HIV-1 infection [25••]. 
Table 1 Summary of published clinical trials of anti-HIV gene therapy (modified from [20])

\begin{tabular}{|c|c|c|c|c|}
\hline Mechanism & Target & Delivery of genes/cell transplantation & Phase & References \\
\hline \multicolumn{5}{|l|}{ HSPC-based studies } \\
\hline RNA decoy & Viral (rev protein) & Retroviral (MMLV) into autologous CD34+ HSPC & Pilot & {$[21]$} \\
\hline Ribozyme & Viral (tat-vpr mRNA) & Retroviral (MMLV) into autologous CD34+ HSPC & I-II & {$[22 \bullet \bullet, 23,24]$} \\
\hline $\begin{array}{l}\text { shRNA RNA decoy } \\
\text { (TAR) ribozyme }\end{array}$ & $\begin{array}{l}\text { Viral (tat-rev mRNA) Viral } \\
\text { (tat protein) Host (CCR5 mRNA) }\end{array}$ & Lentiviral vector (SIN HIV) into autologous CD34+ HSPC & Pilot & {$[25 \bullet \bullet$} \\
\hline $\begin{array}{l}\text { Transdominant negative } \\
\text { Rev mutant }\end{array}$ & Viral (Rev protein) & $\begin{array}{l}\text { Retroviral MoMLV-based vector into allogeneic } \\
\text { CD34+ HSPC }\end{array}$ & Pilot & {$[26]$} \\
\hline \multicolumn{5}{|l|}{ T-cell-based studies } \\
\hline Inhibitory Rev10 protein & Viral (Rev protein) & Plasmid or retroviral -based vector into autologous $\mathrm{T}$ cells & Pilot & {$[27,28]$} \\
\hline HIV-specific T cells & CD4zeta chain & $\begin{array}{l}\text { Retroviral (MMLV-based) vector into autologous } \\
\text { CD4 and CD8 cells }\end{array}$ & II & [29] \\
\hline Ribozyme & Viral (U5 and pol mRNA) & Retroviral (MMLV) into autologous CD4+ T cells & I & {$[30]$} \\
\hline C46 peptide & Viral (env protein) & Retroviral (MMLV) into autologous CD4+ T cells & I & {$[31]$} \\
\hline Ribozyme & Viral (tat-vpr mRNA) & Retroviral (MMLV) into syngeneic CD4+ T cells & Pilot & {$[32,33]$} \\
\hline Antisense & Viral (env mRNA) & Lentiviral vector (LTR HIV) into autologous CD4+ T cells & I-II & {$[34]$} \\
\hline Antisense & Viral (env mRNA) & $\begin{array}{l}\text { Lentiviral vector (VRX496-T; trade name, Lexgenleucel-T) } \\
\text { into autologous CD4+ T cells }\end{array}$ & $\mathrm{I}-\mathrm{II}$ & {$[35 \bullet]$} \\
\hline Antisense & Viral (TAR and/or Rev) & $\begin{array}{l}\text { Retroviral vector into uninfected lymphocytes } \\
\text { from twin donor }\end{array}$ & I-II & {$[36]$} \\
\hline
\end{tabular}

\section{Protein-Based Suppressors}

Normal viral functions can be suppressed by expression of transdominant mutant proteins that act as competitors of cognate HIV-1 proteins. The most experimentally advanced transdominant protein to date is a mutant Rev protein (RevM10) [44], which retains 2 Rev functions: the ability to bind RRE on the viral genome and the ability to form Rev multimers. However, because RevM10 cannot exert its regulatory role in transporting unspliced or singly spliced RNAs from the nucleus to the cytoplasm, susceptible cell lines that express RevM10 exhibit long-term resistance to HIV-1 replication (>30 days). Human CD34+ blood progenitor cells transduced with RevM10 can give rise to T lymphocytes that exhibit significant resistance to challenge with HIV-1 [26].

\section{Clinical Trials of Gene Therapy Using Autologous T Cells}

One cell-based strategy for gene therapy against HIV-1 infection targets autologous $\mathrm{T}$ lymphocytes, including CD4+ or CD8+ $\mathrm{T}$ cells $[27,34]$. Mature $\mathrm{T}$ lymphocytes are easily harvested from the peripheral blood of donors and can be expanded to large numbers in vitro using cell surface stimulation with antibodies to the markers CD3 and CD28 [45]. Targeting mature $\mathrm{T}$ lymphocytes for genetic modification has other advantages, which make it the method of choice for initial evaluation of such gene therapy strategies. The effect of the therapeutic gene on cell survival, viral load, and other parameters can be rapidly evaluated. Autologous T cells can be transduced and immediately selected in vitro using a marker gene included in the vector, so that the reinfused population contains a high percentage of genetically modified cells.

Several clinical trials have evaluated gene therapy products against HIV-1 infection using autologous $\mathrm{T}$ lymphocytes (Table 1).

The first clinical study of a gene therapy approach in HIV-1 infected individuals evaluated the ability of RevM10 to extend the survival of transduced CD4+ T cells in vivo [27]. Despite showing limited and transient duration of engraftment, the study was followed by another one, which evaluated a retrovirus delivery vector for RevM10. Survival of T cells expressing RevM10 was improved relative to that of $\mathrm{T}$ cells transduced with a negative control vector [28] (Table 1). A recent study of conditionally-replicating lentiviral vector expressing a long antisense to HIV-1 targeting HIV-1 env showed that CD4 T cells (VRX496-T) have been safely infused into HIV1-infected patients with well-controlled viremia (discussed above [35•]). Autologous transfer of these cells was safe in chronic viral infection and 6 out of 8 patients who underwent ATI experienced a significant decrease in viral load $(P=0.08)$.

Gene therapy strategies that aim to prevent or disrupt expression of chemokine receptors that facilitate HIV-1 entry into the target cell are particularly attractive. They obstruct the very first step in HIV-1 infection (ie, entry into the target cell), rather than blocking a viral event that occurs after the establishment of the proviral DNA into the cellular genome. The survival advantage of chemokine receptor-modified cells has been demonstrated in animal studies [15•], and has started to demonstrate survival advantages in vivo in HIV-1-infected 
individuals [46]. Clinical studies attempting to mimic the impact of the natural CCR5 deletion on HIV-1 infection are ongoing (NCT01252641 and NCT01044654). These studies evaluate $\mathrm{CD} 4+\mathrm{T}$ cells modified using zinc finger nucleases to edit the CCR5 gene [16] and successful impact of this gene-therapy approach has been recently announced [46].

\section{Clinical Trials of Gene Therapy Using Autologous HSCT}

Despite the demonstration of HIV-1 cure using allogeneic hematopoietic stem cell transplant (HSCT) $[4 \bullet, 5 \bullet \bullet, 6 \bullet]$, the complexity of the method, including the requirement for tissue matching, the prolonged use of immunosuppressive medications to suppress graft vs host disease, and the cost, severely limits its current use. Autologous HSCT, if successful, would restore and maintain CD4 levels after a single treatment, and this has motivated the search for a method using geneticallymodified HSPC (HSPC-GT). Two landmark studies of this type have been discussed, namely those of Mitsuyasu et al [22••] and DiGiusto et al [25••] (Table 1). These studies established feasibility, but showed that new methods were needed if levels of gene modification likely to have an antiHIV-1 effect were to be attained.

The field is now at the point where the first use of busulfanbased conditioning therapy will be used in HIV/AIDS patients. A Calimmune-sponsored trial (NCT01734850) will use a lentivirus vector, encoding 2 HIV-1 entry inhibitors, to transduce both autologous CD4+ T cells and HSPCs in patients who are unable to continue ART due to intolerance or treatment fatigue. The study will test the safety and efficacy of no busulfan vs low dose $(4 \mathrm{mg} / \mathrm{kg})$ and high dose $(8 \mathrm{mg} / \mathrm{kg})$ busulfan used as conditioning therapy. A study from City of Hope (NCT01961063) will test the triple anti-HIV-1 lentivirus used by DiGiusto et al [25••] to determine if a busulfan regimen can be safely used in HIV/AIDS after successful treatment for non-Hodgkin lymphoma. Finally, a study from the Fred Hutchinson Cancer Research Center (NCT01769911) will test whether HSCT-GT, modified to contain an entry inhibitor, can be combined with a methylguanine methyltransferase [MGMT]-based selection method to expand gene-modified progeny cells.

\section{Obstacles Preventing the Application of Gene Therapy to Curing HIV-1 Infection}

There are serious barriers that need to be overcome if genetherapy is to succeed. The main obstacles that currently prevent the application of gene therapy to curing HIV-1 infection are (a) the difficulty of applying a rare disease therapy, such as gene transfer, to the large AIDS population; (b) resolving the safety of cytotoxic conditioning required for cell-based gene therapy; (c) clinical trial design issues, including: 1, correct identification of the target population based on thorough riskbenefit analysis, and 2, the lack of validated cell-based endpoints defining efficacy; (d) development of a safe method for selection of gene-modified cells; and (e) the restrictive cost of manufacturing and technology.

Application of a Therapy Originally Developed to Treat Rare Diseases (ie, Gene Therapy, to a Large Volume Problem, which is the Widespread Infection with HIV-1)

Gene therapy was conceived to treat rare diseases having invariable poor outcome, such as severe combined immunodeficiency (SCID), chronic granulomatous disease (CGD), thalassemia, storage diseases, and other inborn errors of metabolism. It was not until its potential use in "intracellular immunization" was recognized [47] that gene therapy was applied to infectious diseases. Sophisticated processes required for gene therapy, such as efficient stem cell mobilization and collection by leukapheresis, vectored gene delivery, and cell transduction, are complex and expensive. Yet, these technical and financial barriers are accepted in treatment of rare diseases, where few other options are available, given the potential for cure. But the question remains as to whether similarly complex and costly therapy can be applied to the large population of persons with HIV-1, many of whom have restricted access to healthcare.

Lymphoma is probably the best example of a disease that faced similar hurdles. In this disease, autologous HSCT [aHSCT] is successfully used, but only when chemotherapy fails or risk factors suggest a need for HSCT, and optimally when debulking of disease is possible. When first proposed, aHSCT was considered too technically challenging and expensive for wide application, but today aHSCT can be an outpatient procedure, and there are an estimated $\sim 30,000$ 35,000 procedures being performed worldwide every year [48]. More importantly, aHSCT will be curative in $~ 70 \%$ of lymphoma patients. Admittedly, at present, aHSCT is not an economically viable solution to the general problem of HIV/ AIDS. But it is foreseeable that with an eventual HIV-1 vaccine [10••], when the incidence of HIV-1 infection has declined perhaps to levels similar to lymphoma, aHSCT will be not only feasible but desirable as a curative procedure for this disease.

Resolving the Requirement for Cytotoxic Conditioning for Cell-Based Gene Therapy

The first use of a conditioning regimen in patients receiving gene-modified aHSCT was performed in the setting of salvage therapy of AIDS-related lymphoma [25••]. In this pilot clinical study, patients undergoing high-dose chemotherapy and aHSCT were infused with both gene-modified (aHSCT-GT) 
and non-modified HSPC. The study demonstrated the safety and feasibility of the approach following myeloablative conditioning, but clearly such a potentially lethal approach could not be applied to HIV/AIDS patients without lymphoma/leukemia.

An optimized conditioning regimen needs to be determined and used for delivery of HSPC-GT for treatment of HIV/ AIDS. This regimen must balance safety in a nonmalignant population with the requirement for efficient engraftment. Busulfan-based conditioning regimens have been used in clinical trials of gene therapy for the correction of human genetic diseases, including adenosine deaminase deficiency SCID [49, 50 $]$ and X-linked CGD [51]. The safety of busulfan in HIV/AIDS patients remains to be determined in 2 currently active trials (NCT01734850 and NCT01961063). For CD4-based gene therapy, cytoreductive chemotherapy is also under study, using cytoxan as the pre-conditioning therapy (NCT01543152).

\section{Clinical Trial Design Issues for Gene Therapy Strategies Treating Chronic HIV-1 Infection}

It is likely that the newly diagnosed HIV-1 infected population will dichotomize into a group of early treated patients who do very well and mimic elite nonprogressors and those with late AIDS diagnosis who do much less well. We know that currently a large proportion of individuals get tested for HIV-1 infection and start ART very late after initial exposure to the virus [52]. A subset of this latter group will do poorly because of reduced compliance [53]. It is this chronically infected patient population, having AIDSrelated co-morbidities or ART-related toxicities, which will be initially targeted for gene therapy approaches. However, targeting the most relevant patient population, with the most balanced risk:benefit ratio in gene therapy clinical trials, is a serious challenge [54].

The population of chronically HIV-1 infected individuals ranges from poor responders, to ART-intolerant patients, to those with treatment fatigue, and those with AIDS-related malignancy. Each of these subpopulations has a risk:benefit balance and thus a varying justification for gene therapy approaches (Table 2). The principle of justice, as outlined in ethical discussions of clinical research, implies that the population at risk be the eventual population that would be treated should the therapy be successful. Thus, the HIV-1 lymphoma population, although used initially as an ideal design for testing novel gene therapy, is appropriate. But this group is less than optimal for HIV/AIDS gene therapy for several reasons. At a practical level, patients receiving salvage therapy are becoming less available due to improvements in front-line therapy [55]. However, once in remission, these patients are at some risk for myelodysplasia and secondary malignancy due to the completed anti-lymphoma therapy, and this could bias the observations needed to confirm research treatment safety. Also, although useful as a test-of-concept, the results from the HIV-related lymphoma population may not necessarily translate to the treatment of other HIV/AIDS patients targeted for studies testing gene therapy products and non-myeloablative conditioning regimens.

The endpoint of anti-HIV-1 trials require an antiviral effect measured by HIV-1 RNA plasma levels for demonstration of efficacy. This can usually be done with relatively short duration studies. But what if the therapy provides reconstitution of CD4 counts or has an effect on the HIV-1 reservoir that takes months to years? For example, the recent studies with gene modified autologous CD4+ T cells using a zinc finger nuclease to disrupt the CCR5 gene have reported a decrease in HIV1 proviral DNA at 12 months [46]. Admittedly, a profound effect on the reservoir should affect the plasma HIV-1 RNA level, but these studies are usually performed while the research participant remains on ART. Thus, the cell-based effects could occur without an observable effect on HIV-1 RNA plasma levels.

Demonstrating an effect on surrogate markers of outcome, eg, restoration of CD4 count and reversal of inflammation markers, will therefore be the challenge $[18,56]$. This raises the question of whether definition of efficacy in the context of gene therapy for HIV-1 cure will need to be redefined as stabilization of CD4+ T-cell count with or without eradication of HIV-1 reservoir.

\section{Development of a Safe Method for Selection of Gene Modified Cells}

The HSPC-GT trial of DiGiusto et al [25••], although safe using lentivirus transduced HSCT, was used with nontransduced HSCT for ethical reasons related to lymphoma salvage therapy, and resulted in a level of marking that was less than $0.35 \%$ of the progeny PBMC. This low level of marking points out the major limitation with the use of aHSCT-GT, which is the requirement for engraftment of adequate numbers of modified stem cells to overcome the endogenous pool of stem cells. In addition, these types of first-inhuman studies in HIV/AIDS require a back-up unit of HSPC to manage potential hematopoietic complications, which places a further practical challenge on the study to collect sufficient stem cell numbers.

Thus, since non-myeloablative aHSCT-GT will always face the problem of competing endogenous stem cells, a method for selection of protected cells is necessary. Several studies have suggested that HIV-1 itself could be used for selection $[15 \bullet, 57 \bullet \bullet, 58]$, and patients have undergone ATI $[22 \bullet \bullet, 35 \bullet, 46]$ for the purpose of selecting gene-modified cells using the selective pressure put by the actual virus. An alternative is the use of chemical selection, for example with MGMT, which has been used in humans with glioblastoma 
Table 2 Potential target populations for evaluation of gene therapy-based approaches (modified from [54])

\begin{tabular}{|c|c|c|c|c|}
\hline Target population & HIV-1 subgroup & $\begin{array}{l}\text { Risk vs benefit: } \\
\text { appropriate? }\end{array}$ & $\begin{array}{l}\text { Ready } \\
\text { availability }\end{array}$ & Relevant to product development \\
\hline Optimal ART therapy & $\begin{array}{l}\text { HIV-1+ on cART } \\
\text { HIV load: low } \\
\text { CD4 count: high }\end{array}$ & No & No & Possibly \\
\hline Off ART therapy & $\begin{array}{l}\text { HIV-1+ off cART } \\
\text { HIV load: high } \\
\text { CD4 count: high }\end{array}$ & Yes & Yes & Ideal population to observe efficacy \\
\hline $\begin{array}{l}\text { HIV infected, immune } \\
\text { nonresponder (INR) on ART }\end{array}$ & $\begin{array}{l}\text { HIV-1+ on cART } \\
\text { HIV load: low } \\
\text { CD4 count: low }\end{array}$ & Yes & Yes & INR Population suited for needed therapy \\
\hline AIDS malignancy & $\begin{array}{l}\text { HIV-1+ on cART } \\
\text { With NHL } \\
\text { HIV count: low } \\
\text { CD4 count: low or high }\end{array}$ & Yes & No & $\begin{array}{l}\text { Can show test-of-concept, but less applicable for } \\
\text { translation to general AIDS population }\end{array}$ \\
\hline
\end{tabular}

[59] and has recently been shown to protect macaques from SIV infection [57••]. This approach is moving rapidly to clinical testing in HIV/AIDS [60-62], as there is also evidence from animal studies that HIV-1 can induce an expansion of gene-modified cells.

Of course, in addition to providing the means for virusbased selective pressure, ATI is used to determine if a new treatment actually has antiviral activity [22••]. The aHSCTGT trial of Mitsuyasu et al was the first Phase 2 trial of an aHSPC-GT-based therapy in HIV/AIDS and provided a novel design for testing efficacy using ATI. The safety of ATI is critical, and an example of appropriate design for such treatment is shown in Figure 1. The ATI should not begin prior to demonstrating evidence that a minimal, pre-determined level of CD4 gene modification has been achieved. Then, during the ATI, participants should be monitored closely and with stopping rules based on changes in HIV-1 RNA level in plasma, significant reduction in CD4 counts, and clinical signs and symptoms of viremia.

The Restrictive Cost of Manufacturing and Availability of Technology

The high cost associated with gene therapy, whether T-cell- or HSPC-based, challenges the economic viability of this approach. As with aHSCT for lymphoma, in which high initial costs were lowered with experience in the method, it is likely that aHSCT-GT will be inordinately expensive at first and then, as the cost of goods decreases, it will become affordable. At present, it is the cost of goods and services that contributes the major portion of cost to aHSCT-GT, and when there are more providers of these goods, they should become less expensive. In the current context of HIV-1 treatment, where the cost of lifelong ART therapy is estimated to be
Fig. 1 Sample of schema for ATI design in anti-HIV gene therapy trials

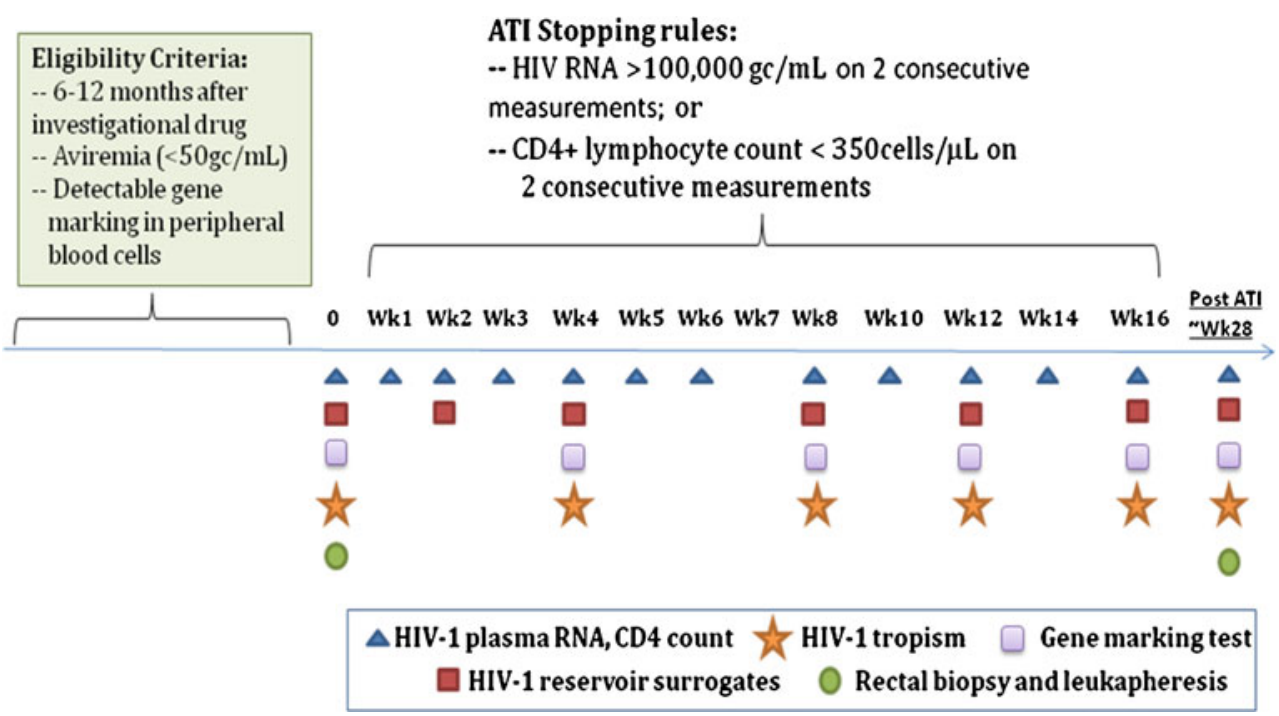


$\$ 420,000-\$ 755,000$ USD per individual, with $73 \%$ of the cost going toward ART $[63,64]$, and even the conversion to generic once daily ART, estimated to only reduce lifetime costs by $\sim \$ 42,000 /$ patient [65], successful gene therapy for HIV-1 could be cost effective [18, 54].

This obviously would be driven by the efficacy of the therapy, but if aHSCT-GT could favorably impact outcome in those HIV/AIDS patients with increased health risks, then aHSCT-GT could result in a significant reduction of the AIDS-related healthcare spending. Admittedly, this is a significant hurdle, but a one-time intervention with a gene therapy approach, which is practical in implementation and could cure HIV-1 infection, would be a viable alternative, both economically and medically.

\section{Conclusions}

Despite the sustained success of ART against HIV-1 infection and the significant improvements made to this regimen, as long as it must be taken daily for a lifetime, there will be a desire to cure HIV-1 infection using a single treatment. It is precisely in this aspect - of showing an impact on the viral reservoir and, therefore, potential for a cure - that the dream of gene therapy continues. Better anti-HIV targets and improved vectors, delivery systems, and cellular processing will contribute to the continued progress of gene therapy approaches against HIV-1 infection. Ideally, gene therapy will eventually rely on a single injection of genetic material that will prevent or control HIV-1 infection. A delivery system, which would result in production of protective humoral immunity, might ultimately fulfill the promise of intracellular immunization [47]. With current breakthroughs [66••, 67], antibodies that recognize and block evolutionarily conserved, but essential structures of the HIV viral envelope, could reinvigorate the search for antibody based HIV vaccines $[10 \bullet \cdot$. Current progress with neutralizing antibodies administered with novel gene delivery highlight the applicability of gene therapy strategies in curing HIV-1 infection [9, 68-70]. One can also anticipate new multiplexed anti-HIV-1 vector combinations that include host restriction factors [71], directed expression of HIV-1 neutralizing antibodies [11•], as well as improved conditioning regimens for T cell and HSPC gene transfer.

\section{Compliance with Ethics Guidelines}

Conflict of Interest Rodica Stan declares that she has no conflict of interest. John A. Zaia has been a consultant for Calimmune Inc.

Human and Animal Rights and Informed Consent This article does not contain any studies with human or animal subjects performed by any of the authors.
Open Access This article is distributed under the terms of the Creative Commons Attribution License which permits any use, distribution, and reproduction in any medium, provided the original author(s) and the source are credited.

\section{References}

Papers of particular interest, published recently, have been highlighted as:

- Of importance

•- Of major importance

1. Deeks SG. HIV infection, inflammation, immunosenescence, and aging. Annu Rev Med. 2011;62:141-55. This reviews the comorbidities associated with HIV-1 infection and reviews novel treatment strategies for dealing with these problems.

2. Davey Jr RT, Bhat N, Yoder C, et al. HIV-1 and T cell dynamics after interruption of highly active antiretroviral therapy (HAART) in patients with a history of sustained viral suppression. Proc Natl Acad Sci U S A. 1999;96:15109-14.

3.• Siliciano RF, Greene WC. HIV Latency. Cold Spring Harb Perspect Med. 2011;1, a007096. doi:10.1101/cshperspect.a007096. This is a complete review of cellular and molecular mechanisms at the basis of HIV-1 latency.

4. Allers K, Hutter G, Hofmann J, et al. Evidence for the cure of HIV infection by CCR5Delta32/Delta32 stem cell transplantation. Blood. 2011;117:2791-9. This is a follow-up description of the AIDS leukemia patient treated in Berlin with a stem cell transplant from a CCR5 negative donor, reviewing the basis for calling this a cure of HIV-1 infection.

5.• Hutter G, Nowak D, Mossner M, et al. Long-term control of HIV by CCR5 Delta32/Delta32 stem-cell transplantation. N Engl J Med. 2009;360:692-8. This is the original report of the "Berlin Patient".

6. Henrich TJ, Hu Z, Li JZ, et al. Long-term reduction in peripheral blood HIV-1 reservoirs following reduced-intensity conditioning allogeneic stem cell transplantation. J Infect Dis. 2013. doi:10. 1093/infdis/jit086. This is a report of 2 recipients of allogeneic blood stem cell therapy, in which the process of transplantation was associated with apparent decrease in HIV-1 reservoir.

7. Archin NM, Liberty AL, Kashuba AD, et al. Administration of vorinostat disrupts HIV-1 latency in patients on antiretroviral therapy. Nature. 2012;487:482-5.

8. McLinden R, Paris R, Polonis V, et al. Association of HIV neutralizing antibody with lower viral load after treatment interruption in a prospective trial (A5170). AIDS. 2012;26:1452.

9. Barouch DH, Whitney JB, Moldt B, et al. Therapeutic efficacy of potent neutralizing HIV-1-specific monoclonal antibodies in SHIVinfected rhesus monkeys. Nature. 2013. doi:10.1038/nature12744.

10.• Picker LJ, Hansen SG, Lifson JD. New paradigms for HIV/AIDS vaccine development. Annu Rev Med. 2012;63:95-111. This is a review of old and new AIDS vaccine strategies with emphasis on novel methods for use of T-cell effector memory cells in vaccine development.

11. Balazs AB, West Jr AP. Antibody gene transfer for HIV immunoprophylaxis. Nat Immunol. 2013;14:1-5. This is a symposium summary that reviewed novel strategies for HIV-1 antibody based immunoprophylaxis.

12. Zhang J, Crumpacker C. Eradication of HIV and cure of AIDS, now and how? Front Immunol. 2013;4:337.

13. Digiusto DL, Kiem HP. Current translational and clinical practices in hematopoietic cell and gene therapy. Cytotherapy. 2012;14:775- 
90. This paper reviews the current practices for blood stem cell gene therapy of AIDS.

14. Levine BL, Cotte J, Small CC, et al. Large-scale production of CD4+ T cells from HIV-1-infected donors after CD3/CD28 costimulation. J Hematother. 1998;7:437-48.

15. Holt N, Wang J, Kim K, et al. Human hematopoietic stem/progenitor cells modified by zinc-finger nucleases targeted to CCR5 control HIV-1 in vivo. Nat Biotechnol. 2010;28:839-47. This paper proved in a murine model the test-of-concept that zinc finger nuclease disruption of CCR5 in blood stem cells could be successfully transplanted into the humanized mouse and alter subsequent HIV-1 infection.

16. Perez EE, Wang J, Miller JC, et al. Establishment of HIV-1 resistance in $\mathrm{CD} 4+\mathrm{T}$ cells by genome editing using zinc-finger nucleases. Nat Biotechnol. 2008;26:808-16.

17. Burnett JC, Rossi JJ. RNA-based therapeutics: current progress and future prospects. Chem Biol. 2012;19:60-71.

18. Kiem HP, Jerome KR, Deeks SG, McCune JM. Hematopoieticstem-cell-based gene therapy for HIV disease. Cell Stem Cell. 2012;10:137-47.

19. Burnett JC, Zaia JA, Rossi JJ. Creating genetic resistance to HIV. Curr Opin Immunol. 2012;24:625-32.

20. Rossi JJ, June CH, Kohn DB. Genetic therapies against HIV. Nat Biotechnol. 2007;25:1444-54.

21. Kohn DB, Bauer G, Rice CR, et al. A clinical trial of retroviralmediated transfer of a rev-responsive element decoy gene into CD34(+) cells from the bone marrow of human immunodeficiency virus-1-infected children. Blood. 1999;94:368-71.

22.• Mitsuyasu RT, Merigan TC, Carr A, et al. Phase 2 gene therapy trial of an anti-HIV ribozyme in autologous CD34+ cells. Nat Med. 2009;15:285-92. This is the first large phase 2 trial of stem cell gene therapy in HIV/AIDS.

23. Amado RG, Mitsuyasu RT, Symonds G, et al. A phase I trial of autologous CD34+ hematopoietic progenitor cells transduced with an anti-HIV ribozyme. Hum Gene Ther. 1999;10:2255-70.

24. Amado RG, Mitsuyasu RT, Rosenblatt JD, et al. Anti-human immunodeficiency virus hematopoietic progenitor cell-delivered ribozyme in a phase I study: myeloid and lymphoid reconstitution in human immunodeficiency virus type-1-infected patients. Hum Gene Ther. 2004;15:251-62.

25.• DiGiusto DL, Krishnan A, Li L, et al. RNA-based gene therapy for HIV with lentiviral vector-modified CD34(+) cells in patients undergoing transplantation for AIDS-related lymphoma. Sci Transl Med. 2010;2:1-8. This is the report of the first lentivirus-based stem cell gene therapy trial in HIV/AIDS.

26. Kang EM, de Witte M, Malech H, et al. Nonmyeloablative conditioning followed by transplantation of genetically modified HLAmatched peripheral blood progenitor cells for hematologic malignancies in patients with acquired immunodeficiency syndrome. Blood. 2002;99:698-701.

27. Woffendin C, Ranga U, Yang Z, et al. Expression of a protective gene-prolongs survival of $\mathrm{T}$ cells in human immunodeficiency virus-infected patients. Proc Natl Acad Sci U S A. 1996;93:288994.

28. Ranga $U$, Woffendin $C$, Verma $S$, et al. Enhanced T cell engraftment after retroviral delivery of an antiviral gene in HIV-infected individuals. Proc Natl Acad Sci U S A. 1998;95:1201-6.

29. Mitsuyasu RT, Anton PA, Deeks SG, et al. Prolonged survival and tissue trafficking following adoptive transfer of CD4zeta gene-modified autologous CD4(+) and CD8(+) T cells in human immunodeficiency virus-infected subjects. Blood. 2000;96: 785-93.

30. Wong-Staal F, Poeschla EM, Looney DJ. A controlled, Phase 1 clinical trial to evaluate the safety and effects in HIV-1 infected humans of autologous lymphocytes transduced with a ribozyme that cleaves HIV-1 RNA. Hum Gene Ther. 1998;9:2407-25.
31. van Lunzen J, Glaunsinger T, Stahmer I, et al. Transfer of autologous gene-modified T cells in HIV-infected patients with advanced immunodeficiency and drug-resistant virus. Mol Ther. 2007;15:1024-33.

32. Cooper D, Penny R, Symonds G, et al. A marker study of therapeutically transduced CD4+ peripheral blood lymphocytes in HIV discordant identical twins. Hum Gene Ther. 1999;10:1401-21.

33. Macpherson JL, Boyd MP, Arndt AJ, et al. Long-term survival and concomitant gene expression of ribozyme-transduced CD4+ Tlymphocytes in HIV-infected patients. J Gene Med. 2005;7:552-64.

34. Levine BL, Humeau LM, Boyer J, et al. Gene transfer in humans using a conditionally replicating lentiviral vector. Proc Natl Acad Sci U S A. 2006;103:17372-7.

35. Tebas P, Stein D, Binder-Scholl G, et al. Antiviral effects of autologous CD4 T cells genetically modified with a conditionally replicating lentiviral vector expressing long antisense to HIV. Blood. 2013;121:1524-33. This is the summary of the results from the study described in reference 23.

36. Morgan RA, Walker R, Carter CS, et al. Preferential survival of CD4+ T lymphocytes engineered with anti-human immunodeficiency virus (HIV) genes in HIV-infected individuals. Hum Gene Ther. 2005;16:1065-74.

37. Zeller SJ, Kumar P. RNA-based gene therapy for the treatment and prevention of HIV: from bench to bedside. Yale J Biol Med. 2011;84:301-9.

38. Chung J, DiGiusto DL, Rossi JJ. Combinatorial RNA-based gene therapy for the treatment of HIV/AIDS. Expert Opin Biol Ther. 2013;13:437-45.

39. Hannon GJ. RNA interference. Nature. 2002;418:244-51.

40. Lee NS, Dohjima T, Bauer G, et al. Expression of small interfering RNAs targeted against HIV-1 rev transcripts in human cells. Nat Biotechnol. 2002;20:500-5.

41. Coburn GA, Cullen BR. Potent and specific inhibition of human immunodeficiency virus type 1 replication by RNA interference. $\mathrm{J}$ Virol. 2002;76:9225-31.

42. Qin XF, An DS, Chen IS, Baltimore D. Inhibiting HIV-1 infection in human T cells by lentiviral-mediated delivery of small interfering RNA against CCR5. Proc Natl Acad Sci U S A. 2003;100:183-8.

43. Wheeler LA, Vrbanac V, Trifonova R, et al. Durable knockdown and protection from HIV transmission in humanized mice treated with gel-formulated CD4 aptamer-siRNA chimeras. Mol Ther. 2013;21:1378-89.

44. Malim MH, McCarn DF, Tiley LS, Cullen BR. Mutational definition of the human immunodeficiency virus type-1 Rev activation domain. J Virol. 1991;65:4248-54.

45. Levine BL, Bernstein WB, Connors M, et al. Effects of CD28 costimulation on long-term proliferation of $\mathrm{CD} 4+\mathrm{T}$ cells in the absence of exogenous feeder cells. J Immunol. 1997;159:5921-30.

46. Sangamo BioSciences Inc. Sangamo BioSciences announces presentation of clinical data demonstrating functional control of viremia in HIV-infected subjects treated with SB-728-T. Presented at the 53rd ICAAC Interscience Conference on Antimicrobial Agents and Chemotherapy. Denver, Colorado; 2013. Available at: http:// www.natap.org/2013/ICAAC/ICAAC_56.htm. Accessed November 11, 2013.

47. Baltimore D. Gene therapy. Intracellular immunization. Nature. 1988;335:395-6..

48. Gratwohl A, Baldomero H, Gratwohl M, et al. Quantitative and qualitative differences in use and trends of hematopoietic stem cell transplantation: a Global Observational Study. Haematologica. 2013;98:1282-90.

49. Aiuti A, Slavin S, Aker M, et al. Correction of ADA-SCID by stem cell gene therapy combined with nonmyeloablative conditioning. Science. 2002;296:2410-3.

50. Candotti F, Shaw KL, Muul L, et al. Gene therapy for adenosine deaminase-deficient severe combined immune deficiency: clinical comparison of retroviral vectors and treatment plans. Blood. 
2012;120:3635-46. This report describes the use of increasing doses of busulfan for conditioning of autologous blood stem cell gene therapy in ADA-SCID patients.

51. Ott MG, Schmidt M, Schwarzwaelder K, et al. Correction of Xlinked chronic granulomatous disease by gene therapy, augmented by insertional activation of MDS1-EVI1, PRDM16, or SETBP1. Nat Med. 2006;12:401-9.

52. Deeks SG, Lewin SR, Havlir DV. The end of AIDS: HIV infection as a chronic disease. Lancet. 2013. doi:10.1016/S0140-6736(13)61809-7.

53. Gardner EM, McLees MP, Steiner JF, et al. The spectrum of engagement in HIV care and its relevance to test-and-treat strategies for prevention of HIV infection. Clin Infect Dis. 2011;52:793-800.

54. DiGiusto DL, Stan R, Krishnan A, et al. Development of hematopoietic stem cell based gene therapy for HIV-1 infection: considerations for proof of concept studies and translation to standard medical practice. Viruses. 2013;5:2898-919.

55. Sparano JA, Lee JY, Kaplan LD, et al. Rituximab plus concurrent infusional EPOCH chemotherapy is highly effective in HIVassociated B-cell non-Hodgkin lymphoma. Blood. 2010;115: 3008-16.

56. Eyal N, Kuritzkes DR. Challenges in clinical trial design for HIV-1 cure research. Lancet. 2013;382:1464-5.

56.• Younan PM, Polacino P, Kowalski JP, et al. Positive selection of mC46-expressing CD4+ T cells and maintenance of virus specific immunity in a primate AIDS model. Blood. 2013. doi:10.1182/ blood-2013-01-482224. This is the first report of the test-ofconcept in a large animal model that MGMT-based expansion of gene modified blood stem cells could protect from SIV infection.

58. Zahn RC, Hermann FG, Kim EY, et al. Efficient entry inhibition of human and nonhuman primate immunodeficiency virus by cell surface-expressed gp41-derived peptides. Gene Ther. 2008;15: $1210-22$.

59. Adair JE, Beard BC, Trobridge GD, et al. Extended survival of glioblastoma patients after chemoprotective HSC gene therapy. Sci Transl Med. 2012;4:133ra57.

60. Beard BC, Trobridge GD, Ironside C, et al. Efficient and stable MGMT-mediated selection of long-term repopulating stem cells in nonhuman primates. J Clin Invest. 2010;120:2345-54.
61. Kiem HP, Wu RA, Sun G, et al. Foamy combinatorial anti-HIV vectors with MGMTP140K potently inhibit HIV-1 and SHIV replication and mediate selection in vivo. Gene Ther. 2010;17:3749.

62. Trobridge GD, Wu RA, Beard BC, et al. Protection of stem cellderived lymphocytes in a primate AIDS gene therapy model after in vivo selection. PLoS One. 2009;4:e7693.

63. Schackman BR, Gebo KA, Walensky RP, et al. The lifetime cost of current human immunodeficiency virus care in the United States. Med Care. 2006:44:990-7.

64. Sloan CE, Champenois K, Choisy P, et al. Newer drugs and earlier treatment: impact on lifetime cost of care for HIV-infected adults. AIDS. 2012;26:45-56.

65. Walensky RP, Sax PE, Nakamura YM, et al. Economic savings vs health losses: the cost-effectiveness of generic antiretroviral therapy in the United States. Ann Intern Med. 2013;158:84-92.

65.• Balazs AB, Chen J, Hong CM, et al. Antibody-based protection against HIV infection by vectored immunoprophylaxis. Nature. 2012;481:81-4. This is the first report of the test-of-concept for vectored immunoprophylaxis of HIV-1 in a murine model and shows that AAV can deliver DNA encoding neutralizaing antibody that protects from HIV-1 challenge.

67. Klein F, Mouquet H, Dosenovic P, et al. Antibodies in HIV-1 vaccine development and therapy. Science. 2013;341:1199-204.

68. Luo XM, Maarschalk E, O'Connell RM, et al. Engineering human hematopoietic stem/progenitor cells to produce a broadly neutralizing anti-HIV antibody after in vitro maturation to human B lymphocytes. Blood. 2009;113:1422-31.

69. Hur EM, Patel SN, Shimizu S, et al. Inhibitory effect of HIVspecific neutralizing IgA on mucosal transmission of HIV in humanized mice. Blood. 2012;120:4571-82.

70. Shingai M, Nishimura Y, Klein F, et al. Antibody-mediated immunotherapy of macaques chronically infected with SHIV suppresses viraemia. Nature. 2013. doi:10.1038/nature12746.

71. Walker JE, Chen RX, McGee J, et al. Generation of an HIV-1resistant immune system with $\mathrm{CD} 34(+)$ hematopoietic stem cells transduced with a triple-combination anti-HIV lentiviral vector. J Virol. 2012;86:5719-29. 